\title{
articles
}

\section{Cannabis use trends in South Africa}

Karl Peltzer, PhD, Dr Habil

Human Sciences Research Council and University of Limpopo, Pretoria

\section{Shandir Ramlagan, MDevSt}

\section{Human Sciences Research Council, Pretoria}

The purpose of this review is to synthesise cannabis use data from surveys, specialised alcohol and drug treatment centres, cannabis-related trauma unit admissions and arrestee studies over the past 12 years in South Africa.

Results indicate that cannabis is the most common illicit substance used in South Africa, with particularly high use among the youth. Current self-reported cannabis use was 5

$10 \%$ among adolescents and $2 \%$ among adults, higher among men than women, higher in urban than rural areas, higher in the urban provinces of Western Cape and Gauteng than the other provinces and higher among coloureds and whites than other racial groups. Cannabis is commonly misused by trauma patients (29-59\%) and is often associated with crime $(39 \%)$. There has been an increase in seizures and treatment demand for cannabis. The current (2006) treatment demand for the whole country was $17 \%$ for cannabis and $3.4 \%$ for cannabis and mandrax (methaqualone), which has implications for treatment service delivery. Screening and brief intervention of substance (cannabis) use should be included in health care settings.

Cannabis is not indigenous to southern Africa, having probably been introduced into the Mozambique area in pre-colonial times by Arab traders many centuries ago. It was adopted by the Khoikhoi as a valued intoxicant and herbal remedy that was chewed or boiled, and was traded from the Xhosa communities living in the eastern parts of South Africa. The smoking of it began after the introduction of the smoking pipe by the European colonialists. It was not until 1928 that cannabis became illegal.'

Historically, the controlled use and consumption of cannabis was ubiquitous throughout southern Africa. Strict rules and values governed the circumstances under which it could be used. Availability was usually controlled by tribal elders. However, in the context of a modernising, increasingly urbanised society, where traditional controls are breaking down, the use of cannabis has now become the domain of the younger user and the polyuser. $^{2,3}$
South Africa is a large producer of cannabis (the world's third largest), most of which is consumed in the southern African region, but at least some of which finds its way to Europe. ${ }^{4}$ Cannabis is cultivated in South Africa, and also imported from neighbouring countries (Swaziland, Lesotho, Mozambique, Zimbabwe), exported to some of the neighbouring countries (e.g. Namibia) and Europe (mainly Holland, UK) and, of course, consumed in South Africa. Cultivation of illicit drugs appears confined to the widespread cultivation of cannabis (but not opium or coca) in the eastern half of South Africa and in some northern areas. There are large rural areas with good conditions for growing cannabis. The estimated area under drug cultivation has been a controversial matter in recent years, with some unrealistically high figures put forward by the authorities. Current estimates put the amount of land under cultivation at 1000 - 1200 hectares. This estimate still places South Africa among the top four herbal cannabis sources in the world, according to Interpol. ${ }^{5}$ A considerable effort is dedicated to both eradication of the crop and to seizures, with large quantities discovered by the police annually. Growing cultivation of cannabis, poor security and lack of intelligence within the police service, have been blamed for increased trafficking of illicit cannabis.

According to Parry and Bennets ${ }^{6}$ cannabis comes second to alcohol as the most extensively used drug in South Africa. Of interest about cannabis is the varying market pricing which is largely determined by packaging forms (e.g. bags, matchboxes, sealed plastic bags), etc., as well as the availability and usage forms (e.g. hashish, compressed dagga, etc.), and weight per unit. The most common form of cannabis is the dried leaves and flowers of the plant, which have a tobacco-like appearance and are either rolled into cigarettes (joints), wrapped in small pieces of newsprint (called zol) or packed into cigars.

According to Leggett ${ }^{7}$ cannabis is consumed by people of all ethnic groups throughout South Africa. Wholesalers of cannabis are mostly African black men with connections to both the rural and urban worlds, who gather large bags in a wide range of transport vehicles, including minibus taxis. They break the bags into smaller, but still sizeable, units, generally called 'arms'. These are distributed to retailers at out-of-the-way locations, typically men's hostels. The retailer, who could be anyone with the connection, then repackages the dagga into still smaller units, typically paper wraps, plastic bank change bags, paper envelopes, or matchboxes. These are then sold in a variety of settings, from specially designated houses, to street corners, petrol stations and 
nightclubs. The street vendor may be an employee of the retailer, working for packets of dagga that he can then re-sell.

Cannabis is the most common primary drug for which adolescents seek treatment, but treatment data provide a poor picture of its use in the general population. Cannabis is the illicit drug most likely to be consumed by high-school students and is commonly used by young rave club attendees. Although many young people do not perceive cannabis to be a drug that gives rise to problems, the South African Community Epidemiology Network on Drug Use (SACENDU) adolescent treatment demand, trauma, and arrestee data reflect the potential that cannabis use has to burden the health, social welfare, and criminal justice systems. ${ }^{8}$

\section{Methods}

Given that cannabis has been available in South Africa for many years, there are numerous studies or sources of data available, yet no consolidated report. To review cannabis use trends in South Africa over the past 12 years, data sources included surveys, specialised alcohol and drug treatment centres (through the South African National Council on Alcoholism and Drug Dependence (SANCA) and SACENDU), cannabis-related trauma unit admissions, and arrestee studies in South Africa over the past 12 years.

Two major national surveys included in the analysis were the 2002 Youth Risk Behaviour Survey (YRBS) among school adolescents, and a national population-based survey in 2005 (SABSSM II). ${ }^{10}$ The YRBS was a cross-sectional national prevalence study among secondary school learners in South Africa and consisted of sampling 23 government schools per province, within which 14766 grades 8, 9, 10 and 11 learners were sampled and 10699 participated. ${ }^{9}$ The survey was planned using a two-stage cluster sample design so as to ensure nationally and provincially representative data collected through selfadministered questionnaires. SABSSM II is a national household study of HIV/AIDS that gathered data on HIV prevalence, behaviour and communication. ${ }^{10}$ The survey design applied a multi-stage disproportionate, stratified sampling approach that yielded 23275 people, of which 16395 were 15 years and older. This nationally and provincially representative sample was collected through interviewer-administered questionnaires. In SABSSM II, cannabis data are here reported the first time, and current cannabis use was defined as use in the past 3 months.

SANCA is a non-governmental organisation whose major objectives are the prevention and treatment of alcohol and other drug dependence. It runs public education activities and provides treatment services for chemically dependent people and their families. As SANCA runs numerous addiction treatment centres in South Africa, they collect their treatment centre data from all clients but unfortunately do not publish such data. SACENDU began recording treatment centre data in 1996. They began in the Western Cape and have added other provinces through the years. In 2007, SACENDU started receiving data from the final four provinces in South Africa, namely Limpopo, Free State, Northern Cape and North West provinces. Currently they provide the most up-to-date information on treatment centre admissions for the whole of South Africa. They also provide descriptive information on the nature and pattern of alcohol and drug use, emerging trends (arrestee and trauma data), risk factors associated with alcohol and drug use, characteristics of vulnerable populations, and consequences in South Africa.

Numerous smaller studies have also been conducted in South Africa, such as in Cape Town secondary schools by Flisher et al. in $1993^{11}\left(N=7\right.$ 340) and in $2003^{12}(N=2$ 779), in Pretoria primary schools by Visser and Moleko ${ }^{13}(N=460)$, in Port Elizabeth schools, grades 8 - 12 by Terblance and Venter ${ }^{14}$ $(N=382)$, in Bele Bele and Pretoria by Mwansa et al. ${ }^{15}$ $(N=303)$ and studies by Peltzer et al. among urban secondary schools ${ }^{16}(N=191)$, among rural secondary schools ${ }^{17}(N=209)$, in a community survey ${ }^{18}(\mathrm{~N}=800)$, among university students ${ }^{19}$ ( $N=799$ ) and among national 25 higher education 3rd/4th-year students, ${ }^{20}$ Plüddemann and Parry ${ }^{21}$ among 1000 arrestees, Pick et al. ${ }^{22}$ among 1671 mine employees, Bowley et al. ${ }^{23}$ among 105 adult trauma patients, Parry et al. ${ }^{24}$ among 1565 trauma patients, Peden et al. ${ }^{25}$ among 254 injured patients, and UNODC ${ }^{4}$ for national seizure statistics.

\section{Lifetime use of cannabis}

As can be seen in Table I, among adolescents, lifetime cannabis use for girls (7\%) has been similar among Cape Town ${ }^{11,12}$ and national ${ }^{9}$ adolescents from 1993 to 2002, while there has been an increase among boys from $13 \%$ to $20 \%$ over the same period. The onset of using cannabis was found to be $4 \%$ for those under the age of 13 years in the 2002 YRBS as can be seen in Table I.

Current use of cannabis among adolescents in two national samples ranged from $9 \%$ in 2002 (YRBS) to $2 \%$ in 2005 (SABSSM II), and the Cape Town samples were between $6 \%$ and $7 \%$.

In a national study among educators older than 20 years $(N=$ 20 626) still lower current cannabis use rates $(0.3 \%)$ were found $10.6 \%$ for males and $0.1 \%$ for females). ${ }^{26}$ Current cannabis use 


\begin{tabular}{|c|c|c|c|c|c|c|}
\hline & \multicolumn{2}{|c|}{$\begin{array}{l}1993 \text { Cape Town } \\
N=7340, G r 8-12^{11}\end{array}$} & \multicolumn{2}{|c|}{$\begin{array}{l}1997 \text { Cape Town } \\
N=2930, \text { Gr } 8 \& 11^{12}\end{array}$} & \multicolumn{2}{|c|}{$\begin{array}{l}2002 \text { YRBS, } 13 \text { - } 19 \text { yrs, } \\
\text { Grade } 8-11^{9}\end{array}$} \\
\hline & Boys & Girls & Boys & Girls & Boys & Girls \\
\hline \multicolumn{7}{|l|}{ Ever used } \\
\hline $13-19$ & $12.8^{*}(1.6)^{\dagger}$ & 7.5 & 19.9 & 7.4 & 20.2 & 7.0 \\
\hline Initiation age <13 & & & & & 5.4 & 3.3 \\
\hline $\begin{array}{l}\text { *Cannabis alone. } \\
\text { †Cannabis and mandrax together. }\end{array}$ & & & & & & \\
\hline
\end{tabular}

among adults was found to be $2 \% 14.4 \%$ among men and $0.3 \%$ among women) in 2005. ${ }^{10}$ The prevalence rates of $4.4 \%$ among men and $0.3 \%$ among women for current cannabis use are lower than those in some other countries such as the USA, with current cannabis use of $8.2 \%$ among men and $6.1 \%$ among women 12 years and above, ${ }^{27}$ and $8.9 \%$ among men and $4.6 \%$ among women 14 years and above in Australia. ${ }^{28}$ Annual cannabis prevalence rates are lower in South America (2.6\%), Asia (2. 1\%) and higher in West and Central Europe (7.4\%), Africa (8. $1 \%$, and North America (10.3\%), USA (31\%). ${ }^{4}$

Among adults in South Africa higher current cannabis use rates were found in urban (2.3\%) than in rural (1.0\%) areas in 2005. ${ }^{10}$ Among youth (15- 24 years, $N=5$ 607) current cannabis use was highest among coloureds $(6.0 \%)$, followed by whites 4.3\%, Indian or Asian 1.8\% and black African 1.1\%. ${ }^{10}$ Among adolescents current cannabis use was found highest in the provinces of Gauteng, Western Cape, Mpumalanga, Free State and Limpopo, ${ }^{9}$ and it was found highest among adults in Western Cape, Gauteng and North West Provinces ${ }^{10}$ (Fig. 1).

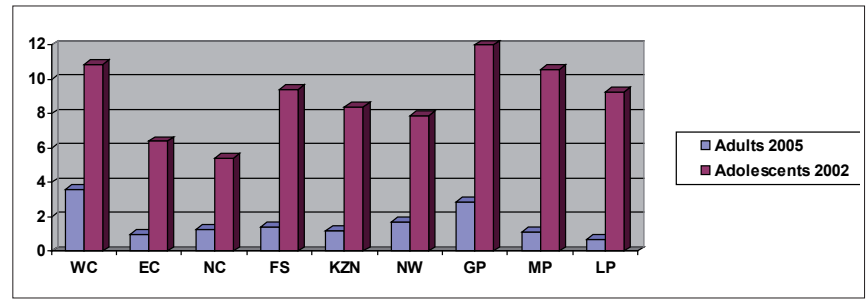

Fig. 1. Current cannabis use among adults ${ }^{10}$ and adolescents ${ }^{9}$ by province (\%).

The range of current use of cannabis among adolescents from $2 \%$ to $9 \%$ in two national samples 9,10 seems to be reflected in various surveys among youth, where it ranges from $2.6 \%$ to $12 \%$. Male youth had far higher current cannabis use prevalence rates than female youth, as is seen in Table II.

\section{Self-reported cannabis use and urine analysis}

Pick et al. ${ }^{22}$ studied 1671 mine employees from 7 mines. Selfreported lifetime cannabis use was $7.2 \%$ and current cannabis use $2.3 \%$, while urine analysis found $9.1 \%$ current cannabis use. Plüddemann and Parry ${ }^{21}$ found among a sample of approximately 1000 arrestees tested and interviewed in three major cities in South Africa that only $54 \%$ of the arrestees who tested positive for cannabis reported using the drug in the past 30 days. Consequently, the prevalence rates of cannabis use in previously reported surveys may be seriously underreported and true figures may well be much higher than the reported figures.

\section{Burden of cannabis use}

\section{Cannabis use and injuries}

Various studies in trauma units show high levels of cannabis use preceding an injury. Bowley et al. ${ }^{23}$ found among 105 adult trauma patients in Johannesburg that $43.7 \%$ were positive for urinary cannabis; women were statistically significantly more likely to have taken cannabis than men. In a study over 3 years from 1999 to 2001 , Parry et al..$^{24}$ found among 1565 trauma patients in 3 major cities, that laboratory screening for cannabis showed that across sites and over the three time periods $25 \%$ and $59 \%$ of patients tested positive for cannabis, and between $7.4 \%$ and $35 \%$ of patients tested positive for methaqualone and cannabis, the so-called 'white pipe' combination. A statistically significant interaction was found between city and year of injury. In Cape Town, the percentage of patients testing positive was significantly higher in 2001 than in 1999 and 2000. Conversely, in Port Elizabeth the percentage of patients testing positive for cannabis was significantly higher in 1999 than in 2001, and for Durban no differences by year were noted. In an earlier study in 1997 in Cape Town, Peden et al. ${ }^{25}$ found lower rates of cannabis use (29.1\%) and 'white pipe' (12.2\%) among 254 injured patients. 


\begin{tabular}{|c|c|c|c|c|c|}
\hline \multirow[b]{2}{*}{ Author } & \multirow[b]{2}{*}{ Year/Institution } & \multirow[b]{2}{*}{$N$} & \multicolumn{3}{|c|}{ Cannabis use in past month (\%) } \\
\hline & & & $\bar{M}$ & $\mathrm{~F}$ & Total \\
\hline 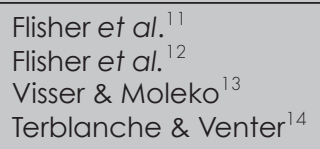 & $\begin{array}{l}\text { 1990/Secondary schools, Cape Town } \\
\text { 1997/Secondary schools, Cape Town } \\
\text { Primary schools, Pretoria } \\
\text { Grades } 8 \text { - 12, Port Elizabeth }\end{array}$ & $\begin{array}{l}7340 \\
2779 \\
460 \\
382\end{array}$ & $\begin{array}{l}9.1 \\
7.3 \\
6.2\end{array}$ & $\begin{array}{l}2.4 \\
3.0 \\
1.7\end{array}$ & $\begin{array}{l}7.0 \\
6.1 \\
3.7 \\
2.8\end{array}$ \\
\hline $\begin{array}{l}\text { Peltzer et al. }{ }^{17} \\
\text { Peltzer et al. }{ }^{16} \\
\text { Mwansa et al. } \\
\text { Peltzer et al. }{ }^{18} \\
\text { Peltzer et al. }{ }^{19} \\
\text { Peltzer et al. }{ }^{20}\end{array}$ & $\begin{array}{l}\text { Urban secondary schools } \\
\text { Rural secondary schools } \\
\text { Bela Bela \& Pretoria } \\
\text { Community survey } \\
\text { University students } \\
\text { National, } 25 \text { higher education 3rd/4th- }\end{array}$ & $\begin{array}{l}191 \\
209 \\
303 \\
800 \\
799 \\
1056\end{array}$ & $\begin{array}{l}12.4 \\
10.7 \\
3.6\end{array}$ & $\begin{array}{l}1.3 \\
2.9 \\
2.2\end{array}$ & $\begin{array}{l}12.0 \\
6.2 \\
4 \\
6.9 \\
6.6 \\
2.6\end{array}$ \\
\hline
\end{tabular}

\section{Cannabis use and crime}

Plüddemann and Parry ${ }^{21}$ found among a sample of 1000 arrestees in three major cities in South Africa that 39\% tested positive for cannabis. The highest rates were in Cape Town (50.2\%), followed by Durban (42.6\%) and Johannesburg $(24.2 \%)$. Among men the rate was $44.5 \%$ and women $16.3 \%$; it was higher among younger age groups: 20 years and less $55.8 \%$ and 21 - 25 years $40.1 \%$; and higher among coloureds (56.4\%) and Indians or Asians (42\%). ${ }^{8}$ The top criminal charge against the arrestee was property offence (31.7\%), violent offence against a person (26.1\%), drug-related offence (of drug supply, possession, production, importation, exportation and cultivation) and other offence $(30.6 \%){ }^{29}$

\section{Cannabis use and HIV}

Based on data from SABSSM II, HIV-positive persons were more likely current cannabis users than HIV-negative persons. ${ }^{30}$ Cannabis use was found to be related to having more than one regular partner and to having irregular partners but not to unprotected first or last sex, as seen in Table III below.

\section{Seizures and treatment demand of cannabis}

There has been a slight increase in seizures ${ }^{4}$ and treatment demand over the past 10 years. With regards to seizures, the
UNODC ${ }^{4}$ reports that from 2000 to 2004 , cannabis seizures have increased from just over $700000000 \mathrm{~kg}$ to just over $800000000 \mathrm{~kg}$. In terms of treatment demand, cannabis abuse alone increased from 14\% in 1999 to $17 \%$ in 2005 of all treatment demand, while cannabis mixed with mandrax has remained stable from 7\% in 1999 to $7 \%$ in 2005 of treatment demand of all drugs. From 1999 to 2005 cannabis treatment demand has been consistently the highest in treatment centres in KwaZulu-Natal (Fig. 2) and cannabis and mandrax treatment demand has been consistently the highest in treatment centres in the Eastern Cape (Fig. 3). In South Africa, as in other countries, there has been an increase in the share of primary cannabis users in treatment populations since 2002, e.g. Denmark 27\%, Greece 7\%, Netherlands 17\%, UK 10\%. ${ }^{4}$

Whether the slight treatment increase is possibly due to increased potency of cannabis used is unknown - South African cannabis is rarely tested for its active chemical, delta-9-tetrahydrocannabinol (THC) levels. Other factors, such as the declining age of the treatment population, may also be responsible. ${ }^{4}$ In a recent HSRC study at drug treatment centres key informants reported an increase in cannabis psychosis due to the high quality of cannabis now available as a result of hydroponic cultivation, as can be seen from the following quotes: ${ }^{31}$

\begin{tabular}{|c|c|c|c|c|c|c|c|}
\hline & $N$ & $\%$ & $\begin{array}{l}\text { HIV-positive } \\
\text { (\%; } 95 \% \mathrm{CI})\end{array}$ & $\begin{array}{l}>1 \text { regular } \\
\text { partner } \\
(\% ; 95 \% \mathrm{Cl})\end{array}$ & $\begin{array}{l}\text { Irregular } \\
\text { partner } \\
(\% ; 95 \% \mathrm{Cl})\end{array}$ & $\begin{array}{l}\text { Unprotected first } \\
\text { sex } \\
(\% ; 95 \% \mathrm{Cl})\end{array}$ & $\begin{array}{l}\text { Unprotected last } \\
\text { sex } \\
(\% ; 95 \% \mathrm{Cl})\end{array}$ \\
\hline $\begin{array}{l}\text { Cannabis use (past } 3 \\
\text { months) }\end{array}$ & 261 & 1.6 & $\begin{array}{l}16.6 ; \\
10.4-25.3\end{array}$ & $\begin{array}{l}19.7 ; \\
11.5-31.8\end{array}$ & $\begin{array}{l}16.1 ; \\
9.9-25.1\end{array}$ & $\begin{array}{l}67.2 ; \\
56.2-76.6\end{array}$ & $\begin{array}{l}48.1 ; \\
35.6-60.8\end{array}$ \\
\hline No cannabis use & 15880 & 98.4 & $\begin{array}{l}13.8 ; \\
12.6-15.0\end{array}$ & $\begin{array}{l}4.7 ; \\
3.9-5.7\end{array}$ & $\begin{array}{l}5.5 \\
4.8-6.4\end{array}$ & $\begin{array}{l}81.4 ; \\
80.2-82.6\end{array}$ & $\begin{array}{l}39.4 ; \\
36.8-42.0\end{array}$ \\
\hline
\end{tabular}




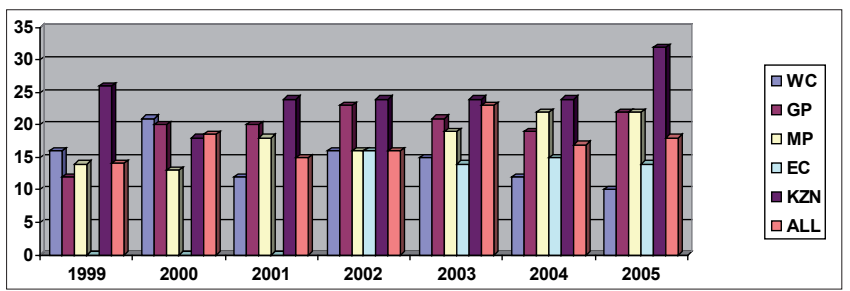

Fig. 2. Percentage of all treatment demand for cannabis as primary drug (source: SACENDU).

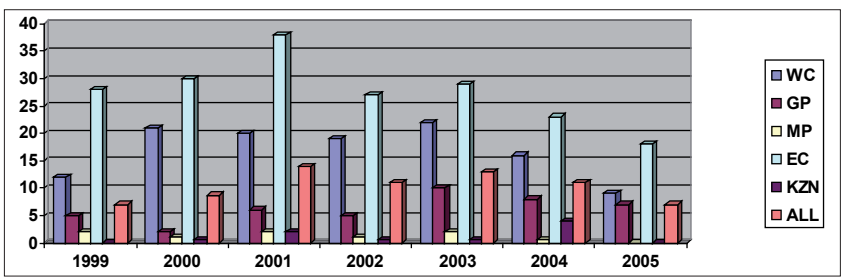

Fig. 3. Percentage of all treatment demand for cannabis and mandrax as primary drug (source: SACENDU).

'The growers are now using hydroponics and therefore we are seeing higher THC levels. This leads to more co-morbid disorders like psychosis. With this new technology now, there is this change.

'There are more people in hospital now and the amount of dagga psychosis is increasing every year.

The current (2006) treatment demand for the whole country was $17 \%$ for cannabis and $3.4 \%$ for cannabis and mandrax. For cannabis usage alone it was highest in treatment centres in KwaZulu-Natal (33\%), followed by Mpumalanga (25\%), Northern Cape (21\%), Gauteng (21\%) and treatment centres in the Free State (20\%), and low in North West (8\%) and Western Cape (8\%). Cannabis and mandrax usage was highest in treatment centres in North West (8\%), Eastern Cape (7\%) and Northern Cape (7\%) and low in treatment centres in Mpumalanga (0\%), Limpopo (0\%) and Free State (2\%) (Table IV).

\section{Conclusion}

Cannabis is the most common illicit substance used in South Africa, in keeping with world trends, with particularly high use among the youth. ${ }^{32}$ Current self-reported cannabis use was 5 - 10\% among adolescents and $2 \%$ among adults, higher among men than women, higher in urban than rural areas, higher in the urban provinces of Western Cape and Gauteng than the other provinces and higher among coloureds and whites than other racial groups. The use of cannabis is widespread among all sectors of South African society, and may be seriously underreported. Cannabis is inexpensive, easy to produce, and the law prohibiting possession is infrequently enforced. ${ }^{32}$ Cannabis is commonly misused by trauma patients (29-59\%) and is often associated with crime $(39 \%)$. There has been an increase in seizures and treatment demand for cannabis. The current (2006) treatment demand for the whole country is $17 \%$ for cannabis and $3.4 \%$ for cannabis and mandrax. The increase in treatment demand has implications for service delivery, especially considering the lack of treatment facilities. ${ }^{31}$ One effective way of reducing cannabis-related problems is routine screening and brief intervention of substance (including cannabis) use in primary and emergency care settings.

The National Department of Social Development, South Africa, is thanked for funding this study.

\section{References}

. Perkel C. Cannabis- the debate continues: a South African perspective. South African Psychiatry Review 2005; 8: 25-30.

2. Eide AH, Acuda SW. Cultural orientation and use of cannabis and inhalants among secondary school children in Zimbabwe. Soc Sci Med 1997; 45(8): 1241-1249.

3. UNODC. South Africa Country Profile on Drugs and Crime: A Regional Overview. Pretoria: UNODC, 2002.

4. UNODC. World Drug Report. Vienna: UNODC, 2006

5. UNODC. Strategic Programme Framework on Crime and Drugs for Southern Africa. Pretoria: UNODC, 2003.

6. Parry CGH, Bennets AL. Alcohol Policy and Public Health in South Africa. New York: Oxford University Press, 1998.

7. Leggett T. Drugs and Crime in South Africa: A Study in Three Cities. Durban: School of Development Studies, University of Natal, 2002.

8. Parry CDH, Plüddemann A, Louw A, et al. The 3-metros study of drugs and crime in South Africa: Findings and policy implications. Am J Drug Alcohol Abuse 2004; 30: 167-185

9. Reddy SP, Panday P, Swart D, et al. Umthenthe Uhlaba Asamila - The South African Youth Risk Behaviours Survey 2002. Cape Town: Medical Research Council, 2003.

10. Shisana $O$, Rehle T, Simbayi LC, et al. South African National HIV Prevalence, HIV Incidence, Behaviour and Communication Survey. Cape Town: HSRC Press, 2005.

11. Flisher AJ, Ziervogel CF, Chalton DO, et al. Risk-taking behaviour of Cape Peninsula high-school students. Part V. Drug use. S Afr Med J 1993; 83(7): 483-485

12. Flisher AJ, Parry CDH, Evans J, et al. Substance use by adolescents in Cape Town Prevalence and correlates. J Adolesc Health 2003; 32: 58-65.

\section{Table IV. Cannabis treatment demand 2006 (N (\%))}

\begin{tabular}{|c|c|c|c|c|c|c|c|c|c|c|}
\hline & EC & $\mathrm{KZN}$ & WC & GP & MP & FS & $\mathrm{LP}$ & NW & NC & Total \\
\hline Number & 776 & 489 & 2660 & 3119 & 501 & 262 & 74 & 181 & 162 & 8224 \\
\hline Cannabis & $116(15)$ & $161(33)$ & $213(8)$ & $655(21)$ & $125(25)$ & $52(20)$ & $17(23)$ & $14(8)$ & $34(21)$ & 1387 (16.9) \\
\hline Cannabis/mandrax & $54(7)$ & $20(4)$ & $80(3)$ & $94(3)$ & 0 & $5(2)$ & 0 & $14(8)$ & $11(7)$ & $278(3.4)$ \\
\hline
\end{tabular}


13. Visser M, Moleko A. High-risk behavior of primary school learners. Urban Health and Development Bulletin 1999; 2(1): 69-77.

14. Terblanche SS, Venter D. Drug abuse amongst high school pupils. Soc Work 1999; 22 $61-178$.

15. Mwansa AN, Rocha-Silva L, Saxena S, et al. Psychoactive substance use among young people: findings of a muti-centre study in three African countries. Contemporary Drug Problems 2004; 31 (2): 329-356

16. Peltzer K, Cherian VI, Cherian L. Substance use among rural secondary school pupils in the Northern Province, South Africa. Journal of Psychology in Africa 1999; 9(1): 58-65.

17. Peltzer K, Cherian VI, Cherian L. Substance use among urban secondary school pupils in South Africa. Southern African Journal of Child \& Adolescent Mental Health 1999; $11(1)$ : 49-55

18. Peltzer K, Promtussananon S, Mashego T-AB. Youth Sexuality in the Context of HIV/AIDS in South Africa. New York: Nova Publishers, 2006.

19. Peltzer K, Malaka DW, Phaswana N. Prevalence of substance use among first year university students in South Africa: baseline assessment for primary prevention intervention. The Social Work Practitioner Researcher 2002; 14(1): 67-79.

20. Peltzer K, Udjo E, Wilson D, et al. Educator Supply and Demand in the South African Public Education System: Integrated Report. Cape Town: Human Sciences Research Council Press, 2005.

21. Plüddemann A, Parry CDH. A short report: self-reported drug use vs. urinalysis in a sample of arrestees in South Africa. Drugs: Education, Prevention and Policy 2003; 10(4): 379383

22. Pick W, Naidoo S, Ajani F, et al. Prevalence of Alcohol and Cannabis Use and Reported Knowledge, Attitudes, and Practice Regarding its Relationship with Health and Safety on Mines in South Africa. Johannesburg: Wits School of Public Health, 2003

23. Bowley DM, Rein $P$, Cherry R, et al. Substance abuse and major trauma in Johannesburg. S Afr J Surg 2004; $41(1):$ 7-10.

24. Parry $C D H$, Plüddemann $A$, Donson $H$, et al. Cannabis and other drug use among trauma patients in Cape Town, Port Elizabeth and Durban, South Africa, 1999-2001. S Afr Med J 2005; 95(6): 429-432.

25. Peden M, Van der Spuy J, Smith P, et al. Substance abuse and trauma in Cape Town. S Afr Med J 2000; 90: 251-255

26. Shisana O, Peltzer K, Zungu-Dirwayi N, et al. The Health of our Educators: a Focus on HIV/AIDS in South African Schools. Cape Town: Human Sciences Research Council Press, 2005

27. Department of Health and Human Services. Results from the 2005 National Survey on Drug Use and Health: National Findings. Rockville: NCADI, 2006

28. Australian Institute of Health and Welfare. 2005 National Drug Strategy Household Survey. Canberra: AlHW, 2005

29. Taylor B, Brownstein HH, Parry C, et al. Monitoring the use of illicit drugs in four countries through the International Arrestee Drug Abuse Monitoring (I-ADAM) program. Criminal Justice 2003; 3(3): 269-286

30. Shisana O, Peltzer K, Zungu-Dirwayi N, et al. HSRC study on alcohol and drug use and HIV prevalence, South Africa 2005. Presented at the MRC/CDC South Africa Workshop: Addressing the link between drugs and HIV in vulnerable populations, Cape Town, 3 August 2006

31. Peltzer K, Ramlagan S, Mohlala G, et al. Substance Abuse Trends in South Africa. Pretoria: Natrional Department of Social Development, 2007.

32. Bhana A, Parry CHD, Myers B, et al. The South African Epidemiology Network on Drug Use (SACENDU) Project, phases 1-8: cannabis and mandrax. S Afr MedJ 2002; 92: 542-547 